\title{
Spectroscopic and Second Harmonic Generations Studies of 5-Bromo-2-methoxybenzonitrile by DFT
}

\author{
A. AJAY PRAVEEN KUMAR ${ }^{1,2}$ and R. GANAPATHI RAMAN ${ }^{1,2 *}$ \\ 'Department of Physics, Noorul Islam Centre for Higher Education, Kumaracoil-629 180, \\ Kanyakumari Dist, Tamil nadu, India. \\ ${ }^{2}$ Nano Computational Laboratory, Department of Nano Technology, Noorul Islam \\ Centre for Higher Education, Kumaracoil-629 180, Kanyakumari \\ Dist, Tamil nadu, India. \\ *Corresponding author E-mail: ajaytenoul@gmail.com \\ http://dx.doi.org/10.13005/ojc/330648
}

(Received: July 20, 2017; Accepted: August 25, 2017)

\begin{abstract}
Equilibrium geometric structure of 5-Bromo-2-methoxybenzonitrile (5B2MOBN) has been carried out through quantum mechanical calculations aided by Density Functional Theory (DFT). Geometrical parameters (bond length, bond angle and dihedral angle) are predicted by using DFT levels employing HF/B3LYP methods with $6-311++G(2 d, p)$ as basis set. The FT-IR and FTRaman spectra of the $5 \mathrm{~B} 2 \mathrm{MOBN}$ were recorded and analyzed by the same level of theory. Frequency doubling and Second Harmonic Generation (SHG) applications are exist in the title molecule, so that the Non Liner Optical (NLO) properties were calculated by the same method with different basis sets.
\end{abstract}

Keywords: 5B2MOBN, DFT, VEDA, TED

\section{INTRODUCTION}

Benzonitrile is the child molecule to the parent molecule ammonia to toluene, which had the enormous changing with the consequence of the particular ratio. ${ }^{1}$ The fragrances, cosmetics, steroid, aromatic alcohols for color removers, solvents for fatty acids, hydrocarbons and oils are used with benzonitrile as a chemical broker. In recent researchers used Benzonitrile as most excellent solvent and versatile precursor chemical intermediate in many derivatives. Benzonitrile is a cyano group Benzonitrile is a colorless, almondlike odor salt, sharp taste ${ }^{2}$ and boiling point at $190.7^{\circ} \mathrm{C}$ at $760 \mathrm{~mm} \mathrm{Hg}$. Benzonitrile compounds had high toxic and irritating product. World Wide Organization set the range of benzonitrile while using the daily usage products. Toxicity effect used for evaluated in prokaryotic and eukaryotic systems. Which evaluation provided the sharp detail and carcinogenicity, chronic toxicity, and mutagenicity ${ }^{4}$. Anisole (methoxybenze) is another form of benzonitrile as it allows for dipolar and dispersion interactions while its capability to be involved in stronger interactions, such as hydrogen bonds, is limited to the role of proton acceptor.In analytical chemistry, the ortho- substituted derivatives of bromo are used as reagents also identified the anesthetic 
problems and brain diseases are cured through these drugs ${ }^{5}$. The benzene ring in 5-Bromo-2methoxybenzonitrile (5B2MOBN) has three substituents such that the bromo and methoxy groups are at meta and ortho position respectively with respect to the cyano group. The methoxy and cyano groups are generally referred to as electron donating substituents in aromatic ring systems. The joining of cyano group in benzonitrile and the aromatic ring creates the migration of the nitrogen atom.

Associations of molecular structural design, nonlinear retort and hyperpolarizability were finding from the vibrational spectra studies of the molecules. The structure of the particle has been leaded by the spectra in juxtaposition through quantum chemical computations. For the spectral approaches unchangeable due to different theoretical methods and series of semi empirical to DFT approaches because every method had its inbuilt capacity ${ }^{6}$. To investigate the structural and vibrational characteristics were executed by HF level $\mathrm{ab}$ initio calculations. The present letter 5-Bromo-2methoxybenzonitrile (5B2MOBN) have inspected both observed and calculations method. The literature review concluded that, there are no publications of the title compound 5B2MOBN using the theoretical methods. From the equilibrium molecular structure, parameters and vibrational assignments help to determine the results of the interior properties of the molecules. Hyperpolarizability and thermodynamical properties are predicted using the HF/DFT methods using the hybrid basis sets.

\section{Experimental details}

The compound 5B2MOBN provided a sturdy purity of larger than $99 \%$ and used as such without any additional refinement by Sigma-Aldrich Chemical Company, the USA. The FT-Raman (FTR) spectrum of 5B2MOBN has been recorded using $1064 \mathrm{~nm}$ line of Nd: YAG laser as excitation wavelength in the region $50-3500 \mathrm{~cm}^{-1}$ on a EZRaman, En wave optronics, USA IFS $66 \mathrm{~V}$ spectrometer. The Fourier transform infra-red (FTIR) spectrum was recorded using 8400 S Bruker, Alpha T, and Germany infrared spectrophotometer using pellet technique in the region $4000-400 \mathrm{~cm}^{-1}$. At the room temperature with scanning speed of $30 \mathrm{~cm}^{-1} \mathrm{~min}^{-1}$ the spectra are traced. The Fig.2 \& Fig. 3 shows the association of both observed and calculated IR and Raman spectra of 5B2MOBN. The above spectra are conceded out at the Department of Nanotechnology, Noorul Islam Centre for Higher Education (NICHE), kumaracoil, Thackalay, Kanyakumari District.

The spectra are computerized using the HF/B3LYP with basic set and the output spectra are monitored threw Gauss sum program, which gives the Raman intensities spectra directly ${ }^{7}$. This program equating the intensity theory of Raman scattering derived relationship and produces the modified Raman intensities data. The assignments give the same results while compared with the three basic sets. The Raman intensity data also merged with the dynamic basic sets which confirmed the formation of methylbenzonitrile. The calculated vibrational frequencies are tabulated as shown in Table. 3.

\section{Computational details}

The GAUSSIAN 09W program is used for predicted the quantum computational calculations of 5B2MOBN with the original version with three parameter functional by way of applying ab-initio Becke-Lee-Yang-Parr hybrid method in correlations HF/B3LYP ${ }^{8}$ level with basis set on Intel Core i3 3.3 $\mathrm{GHz}$ processor personal computer to derive the complete geometry optimization'. Gaussian software is a super positioning tool for developing fields of computational physics like structural analysis, reaction mechanisms, potential energy values, charge distributions and excitation energies of the compound $^{10}$. The single point energy calculation is computing the energies of specific molecular structures and the allied molecular properties are predicted initially. Geometry optimizations calculating equilibrium structure of molecules, optimizing transition structures and energy minimizations at dynamic basic sets. From the second derivatives the energy has been calculated the FT-IR, Raman frequency computing and intensities plots are done by the Gauss sum program. The vibrational assignments with TED are calculated and explained using the Scaled quantum mechanical program using VEDA 4.0. Software ${ }^{11}$. An elevated degree of precision at the customarily considerations along with obtainable linked by the GAUSSVIEW program are made by the molecules vibrational frequency assignments. 


\section{RESULTS AND DISCUSSION}

\section{Optimized geometry}

5B2MOBN compound optimized structure has been illustrated (Fig.1). The stable minimum energy calculated as -3008.21301245 and -3012.6812156 a.u, by HF and B3LYP functional with the standard basis sets. The predicted atomic lengths, atomic angles and torsion angle or dihedral angles from the above method are tabulated in Table.1. There is no data on the optimized structure and equilibrium parameters of 5B2MOBN do not exist in earlier reports through the literature survey. The microwave data are slightly small while compare with theoretical value of the optimized atomic lengths be in the right places to isolated title compound in gaseous phase. The predicted geometrical parameters of the two different basis sets are almost similar. The theoretical values had good agreement with the microwave data. Benzene ring had six carbon atoms and hydrogen atoms which carbons atoms had same lengths and angles and hydrogen atoms had some changes. The molecule have modify in the different chemical and physical assets because of the hydrogen in benzene ring which acts as the trepidation of the valence electron distribution. The recent molecule interactions to the substituents are indicating the benzene ring angular changes ${ }^{12}$.

The molecule has seven carbons bonds, six $\mathrm{C}-\mathrm{H}$, two $\mathrm{C}-\mathrm{O}, \mathrm{C}-\mathrm{N}$ and $\mathrm{C}-\mathrm{Br}$ bonds. There is no crystal structure for the $5 \mathrm{~B} 2 \mathrm{MOBN}$, benzene ring appears a small hazy with carbon to carbon atom bond length next to the substitutions place $(\approx 1.40 \AA)$ longer than the carbon bond (C5-6) in the middle of the ring substituted in the bromo $(\approx 1.36 \AA)$. The distorted elucidates that the substituted on the ring can affect the hybridization and bond lengths of the

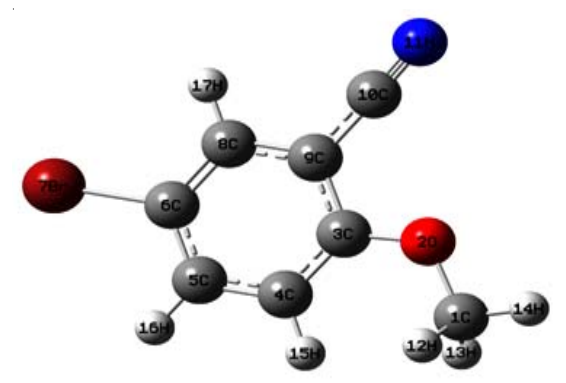

Fig.1. Optimized structure of 5B2MOBN carbon atoms. The bond length of $\mathrm{C}-\mathrm{C}$ increase while compare with benzene ring this shows the angle between substituted atoms has little modified hexagonal structure of the angles. From that result, it is found that the benzene ring has almost the same length of the all carbons bond and deviation should be around $0.005 \AA$ it only corresponds with the earlier reports. The length of the $\mathrm{Ca} \equiv \mathrm{N}$ bond had $1.15 \AA$ is computed by both basic sets and 1.13 $\AA$ is observed for the benzonitrile in early results. Both results had good correlation and the minimum deviation level is $0.02 \AA$, whose result is shorter than the single bond carbon and bromo group as valued is $1.13 \AA$ for both the basis sets. At last, the length of the carbon bromo bond is calculated and merged with the observed value as $1.88 \AA$ which is reported by M. Elanthiraiyan et al., 13. The angles between the bonds have been predicted by an atom that has the corresponding results while comparing with the microwave data.

\section{Vibrational spectra}

There are 45 vibrational assignments are assigns for the 5B2MOBN molecule. In the 45 assignments $\mathrm{C} 1$ point group symmetry. Every vibration intended for $\mathrm{N}$ atomic molecules had $2 \mathrm{~N}$ 3 and N-3 is both bending. As a result 14 in-planes $(\beta)$ and 9 out of plane $(\delta)$ bending are identified for 5 B2MOBN 28 of all 45 vibrations.

In the novel compound of 5B2MOBN are premeditated the harmonic vibrational frequencies at B3LYP level by various basis sets have specified in Table.2. Experimental data and the portrayals alarming the mission also have designated in Table 2 gives the coherent basis for the assignments and shows that the molecules assignments as well as IR \& Raman intensities of the title molecule. In Figs. 2 and 3 shows the comparisons of experimental and calculated spectra.

\section{$\mathrm{CH}$ vibrations}

Four kinds of $\mathrm{CH}$ moieties are calculated in the title compound 5B2MOBN. In this $\mathrm{CH}$ moieties have been listed, six $\mathrm{CH}$ stretching, in plane as well as torsion vibrations. The scenery of the substituent does not align because of these stretching vibrations. The stretching has most feasible frequency between the regions at 
$3100-3000 \mathrm{~cm}^{-1}{ }^{14}$. The calculated stretching vibrations of the title compound region, in between $3202-3005 \mathrm{~cm}^{-1}$. There is no experimental frequencies have been observed. The calculated $\mathrm{CH}$ in-plane bending vibrations of $5 \mathrm{~B} 2 \mathrm{MOBN}$ occurs in the region of $1600-1100 \mathrm{~cm}^{-1}$ and observed FTIR and FTR spectra at 1532, 1517, 1480, 1429, 1250, 1175, $1125 \mathrm{~cm}^{-1}$ and $1482,1312,1214 \mathrm{~cm}^{-1}$, respectively. The $\mathrm{CH}$ out-of-plane bending occurs at the region $950-800 \mathrm{~cm}^{-1}$ generally. The calculated out-of-plane bending vibrations of $5 \mathrm{~B} 2 \mathrm{MOBN}$ are found at 952, 920, 822, $\mathrm{cm}^{-1}$. Observed FTIR and FTR spectraoccurred in the region 876 and $908 \mathrm{~cm}^{-1}$ correspondingly. In this case, the in-plane and out-of-plane bending has been merged with the torsion vibrations. Calculate and observed values good agreement with each other.

\section{$\mathrm{CBr}$ vibrations}

$\mathrm{CBr}$ moieties have been tabulated on the basis of calculated energy distribution and separated three kinds of modes. Six stretching and in-plane bending vibrations are packed in the $\mathrm{CBr}$ atom. The $\mathrm{CBr}$ stretching and bending vibrations are incorporate with each other. In the literature survey, the authors assigned vibrations frequency

Table.1: Equilibrium parameters of 5B2MOBN

\begin{tabular}{|c|c|c|c|c|c|c|c|c|c|}
\hline $\begin{array}{l}\text { Bond } \\
\text { Length }(\AA ̊)\end{array}$ & $\mathrm{HF}$ & B3LYP & Exp & Bond Angle $\left(^{\circ}\right)$ & $\mathrm{HF}$ & B3LYP & Dihedral Angle $\left({ }^{\circ}\right)$ & $\mathrm{HF}$ & B3LYP \\
\hline $\mathrm{C} 1-\mathrm{O} 2$ & 1.43 & 1.43 & 1.44 & $\mathrm{O} 2-\mathrm{C} 1-\mathrm{H} 12$ & 109 & 109 & $\mathrm{C} 9-\mathrm{C} 10-\mathrm{N} 11-\mathrm{H} 14-1$ & 180 & 180 \\
\hline $\mathrm{C} 1-\mathrm{H} 12$ & 1.07 & 1.07 & 0.98 & $\mathrm{O} 2-\mathrm{C} 1-\mathrm{H} 13$ & 109 & 109 & $\mathrm{C} 9-\mathrm{C} 10-\mathrm{N} 11-\mathrm{H} 14-2$ & 180 & 180 \\
\hline $\mathrm{C} 1-\mathrm{H} 13$ & 1.07 & 1.07 & 0.95 & $\mathrm{O} 2-\mathrm{C} 1-\mathrm{H} 14$ & 109 & 109 & H12-C1-O2-C3 & -90 & -60 \\
\hline $\mathrm{C} 1-\mathrm{H} 14$ & 1.07 & 1.07 & 0.95 & $\mathrm{H} 12-\mathrm{C} 1-\mathrm{H} 13$ & 109 & 109 & $\mathrm{H} 13-\mathrm{C} 1-\mathrm{O} 2-\mathrm{C} 3$ & 30 & 60 \\
\hline O2-C3 & 1.3 & 1.43 & 1.37 & $\mathrm{H} 12-\mathrm{C} 1-\mathrm{H} 14$ & 109 & 109 & $\mathrm{H} 14-\mathrm{C} 1-\mathrm{O} 2-\mathrm{C} 3$ & 150 & 180 \\
\hline C3-C4 & 1.4 & 1.4 & 1.402 & $\mathrm{H} 13-\mathrm{C} 1-\mathrm{H} 14$ & 109 & 109 & C1-O2-C3-C4 & 0 & -30 \\
\hline C3-C9 & 1.4 & 1.4 & 0.95 & $\mathrm{C} 1-\mathrm{O} 2-\mathrm{C} 3$ & 120 & 109 & C1-O2-C3-C9 & 180 & 150 \\
\hline C4-C5 & 1.36 & 1.4 & 1.438 & $\mathrm{O} 2-\mathrm{C} 3-\mathrm{C} 4$ & 120 & 120 & O2-C3-C4-C5 & 180 & 180 \\
\hline $\mathrm{C} 4-\mathrm{H} 15$ & 1.07 & 1.07 & 0.95 & O2-С3-С9 & 120 & 120 & $\mathrm{O} 2-\mathrm{C} 3-\mathrm{C} 4-\mathrm{H} 15$ & 0 & 0 \\
\hline C5-C6 & 1.36 & 1.4 & 1.384 & C4-C3-C9 & 119 & 120 & C9-C3-C4-C5 & 0 & 0 \\
\hline $\mathrm{C} 5-\mathrm{H} 16$ & 1.07 & 1.07 & 0.95 & C3-C4-C5 & 120 & 120 & C9-C3-C4-H15 & -180 & -180 \\
\hline $\mathrm{C} 6-\mathrm{Br} 7$ & 1.91 & 1.91 & 1.88 & C3-C4-H15 & 120 & 120 & O2-C3-C9-C8 & -180 & 180 \\
\hline C6-C8 & 1.36 & 1.4 & 1.38 & $\mathrm{C} 5-\mathrm{C} 4-\mathrm{H} 15$ & 120 & 120 & O2-C3-C9-C10 & 0 & 0 \\
\hline C8-C9 & 1.4 & 1.4 & 1.38 & C4-C5-C6 & 121 & 120 & C4-C3-C9-C8 & 0 & 0 \\
\hline $\mathrm{C} 8-\mathrm{H} 17$ & 1.07 & 1.07 & 0.95 & $\mathrm{C} 4-\mathrm{C} 5-\mathrm{H} 16$ & 120 & 120 & C4-C3-C9-C10 & 180 & 180 \\
\hline C9-C10 & 1.4 & 1.4 & 1.4 & $\mathrm{C} 6-\mathrm{C} 5-\mathrm{H} 16$ & 120 & 120 & C3-C4-C5-C6 & 0 & 0 \\
\hline \multirow[t]{15}{*}{ C10-N11 } & 1.15 & 1.15 & 1.13 & $\mathrm{C} 5-\mathrm{C} 6-\mathrm{Br} 7$ & 120 & 120 & C3-C4-C5-H16 & 180 & 180 \\
\hline & & & & C5-C6-C8 & 121 & 120 & $\mathrm{H} 15-\mathrm{C} 4-\mathrm{C} 5-\mathrm{C} 6$ & 180 & 180 \\
\hline & & & & $\mathrm{Br} 7-\mathrm{C} 6-\mathrm{C} 8$ & 120 & 120 & $\mathrm{H} 15-\mathrm{C} 4-\mathrm{C} 5-\mathrm{H} 16$ & 0 & 0 \\
\hline & & & & $\mathrm{C} 6-\mathrm{C} 8-\mathrm{C9}$ & 120 & 120 & $\mathrm{C} 4-\mathrm{C} 5-\mathrm{C} 6-\mathrm{Br} 7$ & -180 & -180 \\
\hline & & & & $\mathrm{C} 6-\mathrm{C} 8-\mathrm{H} 17$ & 120 & 120 & C4-C5-C6-C8 & 0 & 0 \\
\hline & & & & $\mathrm{C} 9-\mathrm{C} 8-\mathrm{H} 17$ & 120 & 120 & $\mathrm{H} 16-\mathrm{C} 5-\mathrm{C} 6-\mathrm{Br} 7$ & 0 & 0 \\
\hline & & & & С3-С9-С8 & 119 & 120 & $\mathrm{H} 16-\mathrm{C} 5-\mathrm{C} 6-\mathrm{C} 8$ & -180 & 180 \\
\hline & & & & C3-C9-C10 & 120 & 120 & C5-C6-C8-C9 & 0 & 0 \\
\hline & & & & C8-C9-C10 & 120 & 120 & $\mathrm{C} 5-\mathrm{C} 6-\mathrm{C} 8-\mathrm{H} 17$ & 180 & 180 \\
\hline & & & & & & & $\mathrm{Br} 7-\mathrm{C} 6-\mathrm{C} 8-\mathrm{C} 9$ & -180 & 180 \\
\hline & & & & & & & $\mathrm{Br} 7-\mathrm{C} 6-\mathrm{C} 8-\mathrm{H} 17$ & 0 & 0 \\
\hline & & & & & & & C6-C8-C9-C3 & 0 & 0 \\
\hline & & & & & & & C6-C8-C9-C10 & -180 & -180 \\
\hline & & & & & & & $\mathrm{H} 17-\mathrm{C} 8-\mathrm{C} 9-\mathrm{C} 3$ & -180 & 180 \\
\hline & & & & & & & $\mathrm{H} 17-\mathrm{C} 8-\mathrm{C} 9-\mathrm{C} 10$ & 0 & 0 \\
\hline
\end{tabular}


range of $1129-480 \mathrm{~cm}^{-1}$ while the Carbon interactions with others heavy atoms like $\mathrm{Cl}, \mathrm{Br}, \mathrm{I}^{15}$. The 5B2MOBN compound has the strong both vibrations in the region of 876,665 and $310,258,126 \mathrm{~cm}^{-1}$ found from IR and Raman spectrum, respectively. Torsion vibrations calculated frequency of the title molecule transpire in the range at $319,223,116 \mathrm{~cm}^{-1}$. These vibrations are very well agreed with literature survey.

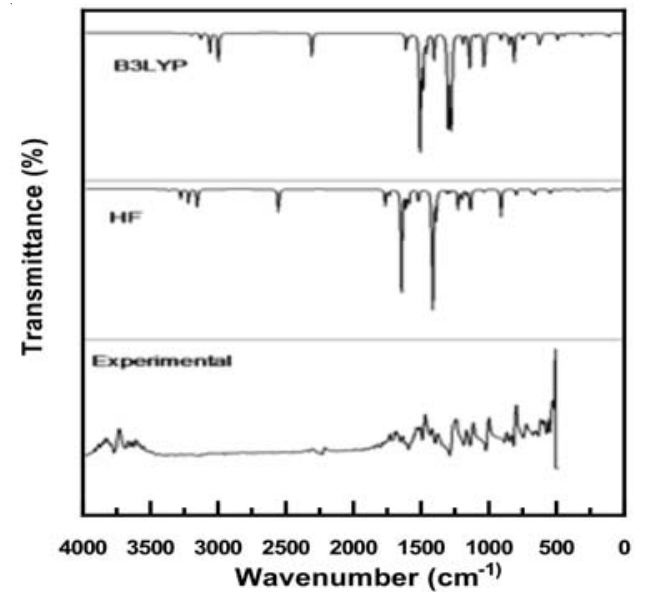

Fig.2. Experimental and theoretical DFT/B3LYP FTIR of 5B2MOBN

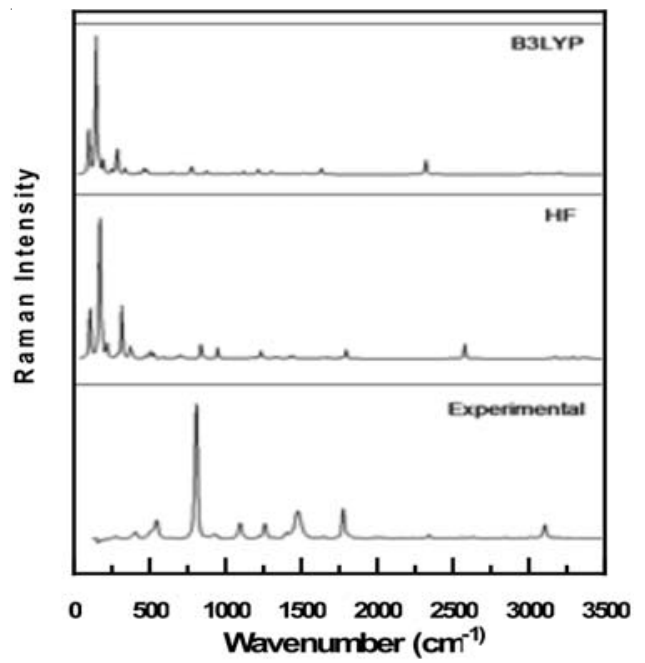

Fig.3. Experimental and theoretical DFT/B3LYP FTR of 5 B2MOBN

$\mathrm{Ca} \equiv \mathrm{N}$ vibrations

In the $\mathrm{CN}$ moieties, stretching frequency is the intensively localized one due to the TED for this frequency contains good contribution from that constant value of stretching force. In the benzonitrile molecule, the cyano group $(\mathrm{Ca} \equiv \mathrm{N})$ vibrational wave number is almost unchanged because of it joined together the phenyl ring as a new substituent. For the aromatic compound which bears a $\mathrm{Ca} \equiv \mathrm{N}$ group attached to the ring, a band of good intensity has been absorbed in the region $2240-2221 \mathrm{~cm}^{-1} 16$ and it is being attributes to $\mathrm{Ca} \equiv \mathrm{N}$ stretching. $\mathrm{Br}$ is the electron acceptor groups; it decrease the IR band intensity and increases the wave number value to the higher limit of the characteristic spectral region. $\mathrm{CH}_{3}$ is the electrons donating groups, it increase IR intensity and decrease wave number value ${ }^{17}$. These electron acceptor groups are the main impact for the shifting for $\mathrm{Ca} \equiv \mathrm{N}$ vibrational wave number. FTR spectra frequency at $2338 \mathrm{~cm}^{-1}$ for $\mathrm{Ca} \equiv \mathrm{N}(\mathrm{v})$ vibrations found for 5B2MOBN. The calculated wavenumbers of stretching vibrations at $2313 \mathrm{~cm}^{-1}$ coincide with the FTIR value. This is the ideal frequency of the whole molecule which confirmed the CN stretching with $90 \%$ assignment. The bending vibrations $(\beta)$ of the molecule for Raman and FTIR spectra spotted at 424, $310,126 \mathrm{~cm}^{-1}$ and $665,626 \mathrm{~cm}^{-1}$, respectively ${ }^{18}$. These experiment values are well agreement with the calculated frequencies.

\section{C-C and $\mathbf{C}-\mathbf{C}-\mathbf{C}$ vibrations}

Benzonitriles are the substituents cyanogens groups and the benzene ring has almost the same length of the all carbons bond and minimum deviation. The thirteen stretching (mode no. 13, 14, 20, 22, $27,30,31,32,33,34,39,40,41)$ carbon vibrations slouch in the region $500-1850 \mathrm{~cm}^{-1}$ and ten bending of vibrations slouch above the region $1300 \mathrm{~cm}^{-1} 19$. From the research, the six similar carbon bonding can produce benzene the same time that ring vibrating the seven $\mathrm{C}-\mathrm{C}$ stretching modes are scanned through FTIR in the region at 1646, 1532, $1429,1387,1250,1125,876 \mathrm{~cm}^{-1}$ and the five FTR at $2338,1644,1312,1214,424 \mathrm{~cm}^{-1}$ coincides each other. The recorded spectral values of $\mathrm{C}-\mathrm{C}-\mathrm{C}$ bending modes at 1010, 876, 665, 626 and 1030, $126 \mathrm{~cm}^{-1}$ values are equal with predicted numerical.

\section{CCCC torsional vibrations:}

The ring torsions have been assigned in the region at below $800 \mathrm{~cm}^{-1}$ which is discussed in present paper referred by earlier reports ${ }^{20}$. The IR and Raman spectra peak observe in the region at $734,601,520$ and $714,604,490 \mathrm{~cm}^{-1}$ respectively. These peaks have been calculated at the region at $751,595,501,402,146,116 \mathrm{~cm}^{-1}$ by B3LYP methods which are well merge with observed values. And these wavenumbers are mixed with $\mathrm{CCCN}$ torsions in the investigated molecules. 


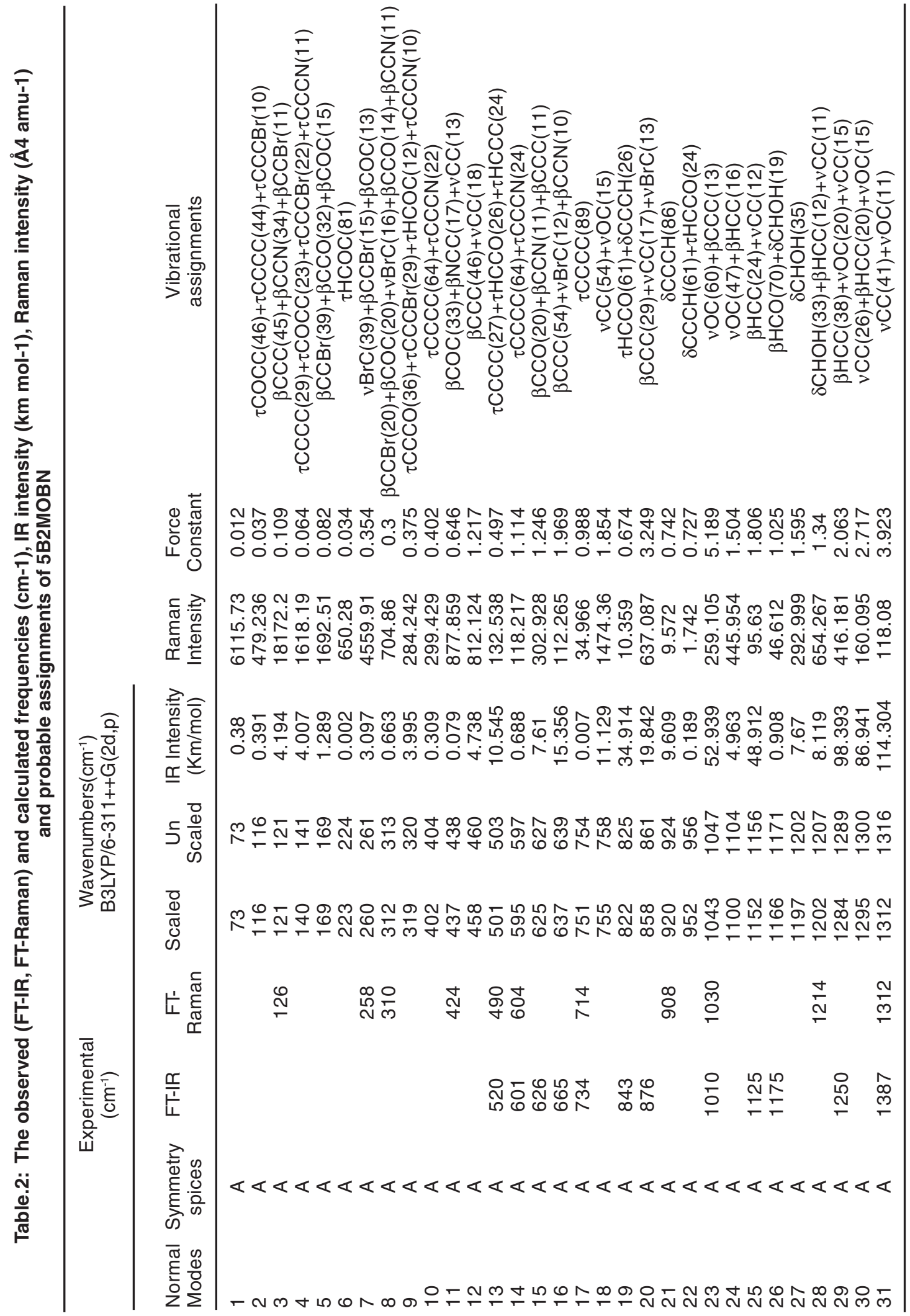




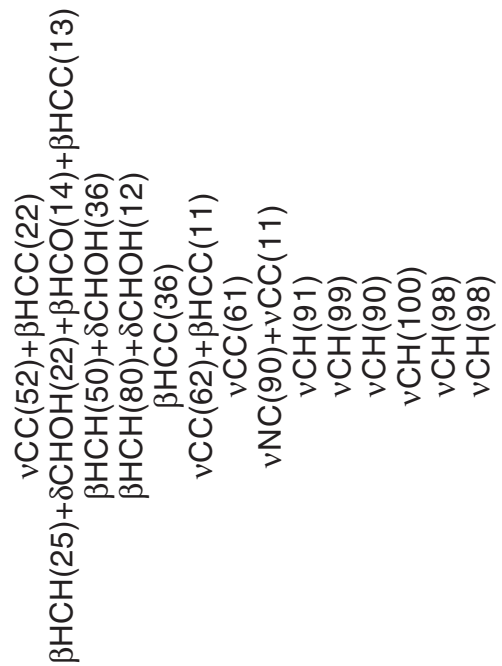

N

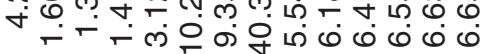

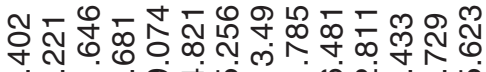

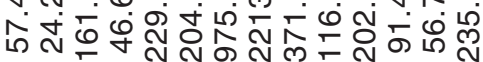

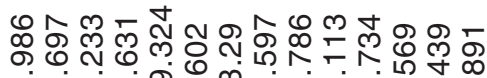
लें 유

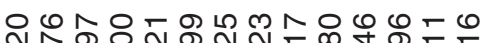

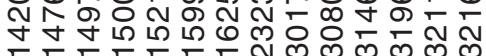

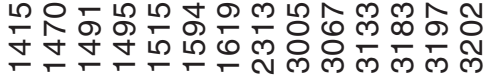

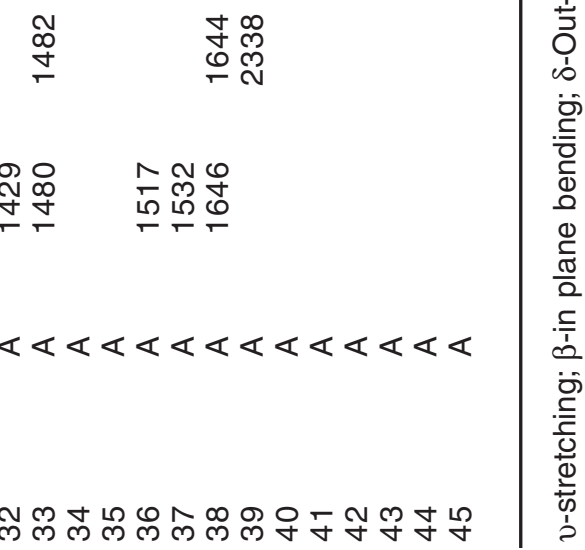

\section{C-O vibrations}

The observed region $1360-1260 \mathrm{~cm}^{-1}$ is the best frequency vibration for carbonyl group ${ }^{21}$. For the reason that of its sky-scraping intensity ${ }^{22}$ and the comparatively interference-free province in which it occurs, this band is logically effortless to distinguish. Vijay Rastogi et al., assigned vibrations of $\mathrm{C}-\mathrm{O}$ band observed at $1348 \mathrm{~cm}^{-1}$ (DFT) as the stretching mode. M. Suhasini et al., assigned stretching vibrations of $\mathrm{C}-\mathrm{O}$ band observed at 1646 , $1629 \mathrm{~cm}^{-1}$ in the FTIR spectrum and 1633 in Raman spectrum. In the current vocation, the bands observed in $1387,1250,1010 \mathrm{~cm}^{-1}$ at the infrared and $1312,1030 \mathrm{~cm}^{-1}$ in Raman spectrum are assigned to the $\mathrm{C}=\mathrm{O}$ stretching mode of vibrations. The hypothetically pragmatic frequencies are in very good agreement with the experimental frequencies. These $\mathrm{C}=\mathrm{O}$ vibrations are also shown fairly good coherent in literature survey. The 2-(4bromophenyl)-2-oxoethyl-3-methylbenzoate has observed at1385 $\mathrm{cm}^{-1}$ in (C-O) stretching mode ${ }^{23}$. For the title compound, has assigned the stretching at $1387 \mathrm{~cm}^{-1}$ (DFT) and $1312 \mathrm{~cm}-1$ (Raman).

\section{Optical property}

The hyperpolarizability is contributed by the structure, bonding and vibrational of the molecule. The dipole moment $(\mu)$ and hyperpolarizability of the benzonitrile is high. In the recent molecule has been calculated the enhanced hyperpolarizability value which is due to the substituent of the benzonitrile. The bond and vibrational results are confirmed the envelope to the hyperpolarizability enlargement of the 5B2MOBN molecule. In the fields such as telephoning, signal transferring and fiber optic cables, NLO enhance the functions for the developing technologies like frequency modulation, optical changing, optical controlling and optical logical circuits ${ }^{24}$. The first hyperpolarizability $(\beta)$ polarizability $(\alpha)$ and anisotropy of polarizability ${ }^{25}$ $(\Delta \alpha)$ of 5 B2MOBN is calculated using DFT with the above basic set and can be evaluated using equations (1) (2) (3) respectively. The Table.3 listed the numerical values of above mentioned parameters. The electric is the task for the energy of the scheme because an electrical meadow exists in the molecule. 333 matrix is used for determined the hyperpolarizability. Kleinman symmetry diminished the 27 mechanisms into 10 mechanisms ${ }^{26}$. 


$$
\begin{aligned}
& \mu=\left(\mu_{x}^{2}+\mu_{y}^{2}+\mu_{z}^{2}\right)^{\frac{1}{2}} \\
& \alpha=\frac{1}{3}\left(\alpha_{x x}+\alpha_{y y}+\alpha_{z z}\right) \\
& \Delta \alpha=\frac{1}{\sqrt{2}}\left[\left(\alpha_{x x}-\alpha_{y y}\right)^{2}+\left(\alpha_{x x}-\alpha_{z z}\right)^{2}+\left(\alpha_{z z}-\alpha_{x x}\right)^{2}+\right. \\
& \left.6 \alpha_{x z}^{2}+6 \alpha_{x y}^{2}+6 \alpha_{y z}^{2}\right]^{1 / 2} \\
& \beta=\left[\left(\beta_{x x x}+\beta_{x y y}+\beta_{x z}\right)^{2}+\left(\beta_{y y}+\beta_{z y y}+\beta_{y x x}\right)^{2}+\left(\beta_{z z}+\beta_{z x}+\beta_{z y y}\right)^{2}\right]^{1 / 2}
\end{aligned}
$$

The calculated values of $\alpha$ and $\beta$ are $2587.1041 \times 10^{-33} \mathrm{esu}$ and $1767.4709 \times 10^{-33} \mathrm{esu}$.
Ideal molecule urea is used for determined the comparative purpose. The compound has the values $2.151 \mathrm{D}$ and $1.7674 \times 10^{-33}$ esu of $\mu$ and $\beta$ respectively. The $\mu$ of compound is approximately 1.56 times greater than that of urea and the $\beta$ of compound is 4.74 times greater than that of urea $(\mu$ and $\beta$ of urea are 1.3732 Debye and $0.3728 \times 10$ ${ }^{30} \mathrm{esu}$ with the same method). The recent molecule has steady state potential for NLO applications like frequency doubling and communications that is confirmed by the recent research ${ }^{27}$.

Table.3: Optical properties of 5B2MOBN

\begin{tabular}{lccccc}
\hline Parameters & $\begin{array}{c}\text { B3LYP/6- } \\
\text { 311++G(2d,p) }\end{array}$ & $\begin{array}{c}\text { B3LYP/6- } \\
311++G(d, p)\end{array}$ & Parameters & $\begin{array}{c}\text { B3LYP/6- } \\
311++G(2 d, p)\end{array}$ & $\begin{array}{c}\text { B3LYP/6- } \\
311++G(d, p)\end{array}$ \\
\hline$\mu_{x}$ & 0.5231839 & 0.5425969 & $\beta_{x x x}$ & 150.575 & 106.644 \\
$\mu_{y}$ & -0.8954072 & -0.907651 & $\beta_{x x y}$ & 15.7744 & 21.0226 \\
$\mu_{z}$ & -1.8846654 & -1.8997386 & $\beta_{x y y}$ & 30.2549 & 25.8986 \\
$\mu$ & 2.1511 Debye & $2.1742 D e b y e$ & $\beta_{y y y}$ & -83.021 & -85.125 \\
$\alpha_{x x}$ & 169.9052472 & 166.3009652 & $\beta_{x x z}$ & 57.1005 & 43.6984 \\
$\alpha_{x y}$ & -21.2152338 & -21.6155069 & $\beta_{x y z}$ & -45.732 & -46.307 \\
$\alpha_{y y}$ & 86.3503433 & 82.8495989 & $\beta_{y y z}$ & -12.325 & -15.073 \\
$\alpha_{x z}$ & 12.4692927 & 11.681339 & $\beta_{x z z}$ & 17.2665 & 7.27064 \\
$\alpha_{y z}$ & 19.3370896 & 19.6332495 & $\beta_{y z z}$ & 16.661 & 18.7448 \\
$\alpha_{z z}$ & 129.6060502 & 126.0585381 & $\beta_{z z z}$ & -37.437 & -47.344 \\
$\alpha_{0}$ & $299.4576 \times 10^{-33}$ esu & $144.5724 \times 10^{-33}$ esu & $\beta_{0}$ & $1767.4709 \times 10^{-33}$ esu $1280.1140 \times 10^{-33}$ esu \\
$\alpha$ & $2587.1041 \times 10^{-33}$ esu & $291.1700 \times 10^{-33}$ esu & & \\
\hline
\end{tabular}

\section{CONCLUSION}

From the HF/DFT methods by $6-311++\mathrm{G}$ $(2 \mathrm{~d}, \mathrm{p})$ basis sets, computed the geometrical parameters and optimized structure. The research the experimental FT-IR, FTR spectroscopic studies are investigated first time and explained vibrations assignments with TED\% using the B3LYP method.
The theoretical spectra are predicted using computational methods and well agreement with experimental results. The $\mu$ and $\beta$ values of the compound were 1.56 and 4.74 times greater than that of urea, respectively. These properties show that the title compound 5B2MOBN had good chemical stability, bioactivity and optics applications for helping the future researchers and innovative thinkers.

\section{REFERENCES}

1. Geskin, V.M.; Lambert,C.; Bredas,J L. J. O.Am. Chem. Soc. 2003, 125(50), 15651-15658.

2. Ajaypraveenkumar, A.; Raman, R.G. J. Chem. Pharm. Sci. 2017, 27-41.

3. Chaitanya,K.Spectrochim. Acta, Part A. 2012, 86, 159- 173 .

4. Binoy,J.; James, C.; Hubert Joe,L.; Jaya kumar, V.
S. J. O. mol.Struc., 2006, 784 (1), 32-46.

5. Ajaypraveenkumar, A.; Raman, R.G. J. Chem. Pharm. Sci. 2017, 10, 1309-1316.

6. Ventura, C.; M.; Kassab, E.; Buntinx, G.; Poizat, O.Phys. Chem. Chem. Phys. 2000, 2(20), 4682-4689.

7. Sundaraganasan, N.; Elango, G.; Sebastian, 
S.; Subramani, P. Indian. J. Pure Applied Phys. 2009, 47, 481-490.

8. Parr, R.R.; Yang, R.G. Density Functional Theory of Atoms and Molecules, Oxford University Press, New York, USA, 1989.

9. Vien, D.L.; Colthup, N.B.; Fateley, W.G.; Grasselli, J.G. The Handbook of Infrared and Raman Characteristics, Academic Press, New York, 1991.

10. Murugan, M.; Balachandran ,V.; Karnan, M. J. Chem. Pharm. Res. 2012, 4(7), 3400-3413.

11. Almosawe, A.J.; Saadon, H.L.Chin. Opt. Lett. 2013, 11(4), 041902-041906.

12. Arjunan,V.; Raj, A.; Santhanam,R.; Marchewka, M.K.; Mohan,S. Spectrochim. Acta, Part A. 2013, 102, 327-340.

13. Elanthiraiyan,M.; Jayasudha, B.; Ariva zhagan, M. Spectrochim. Acta, Part A. 2015, 134, 543-552.

14. Al-Otaibi, J.S. Int. J. Pharm. Sci. Rev. Res. 2016, 37 (2), 264-270.

15. Samdal,S.; Strand, T.G.; Tafipolsky, M.A.; Vilkov,L.V.; Popik, M.V.; Volden, H.V.J. Mol.Struct. 1997, 435(1), 89-99.

16. Miehlich,B.; Savin,A.; Stoll,H.; Preuss,H. Chem. Phys.Lett. 1989, 157(3), 200-206.
17. Colthup, N.B.; Daly, I.H.;Wiverly, S.E. Introductions Infrared and Raman Spectroscopy, third ed., Academic Press, Newyork, 1990.

18. Prysta, D.A.; Anderson, A.; Torrie, B.H.J. Ram. Spectrosc. 1994, 25(2), 175.

19. Premkumar,S.;Jawahar,A.; Mathavan,T.; Kumara Dhas,M.; Sathe, V.G.;Benial, A.M.F. Spectrochim. Acta, Part A. 2014, 129, 74-83.

20. Chaitanya,K.; Santhamma,C.; Prasad, K.V.; Veeraiah,V.J. Mol. Sci. 2011, 3(1), 1-22.

21. Mohan,J. Organic Spectroscopy Principle and Applications, second edition, Narosa Publishing House, New Delhi, 2001.

22. Kumar, J.S.; Jeyavijayan,S.; Arivazhagan,M. Spectrochim. Acta, Part A. 2015, 136, 234-246.

23. Diwaker, Chidan Kumar, C.S.; Kumar, A.; Chandraju, S.; Fun, H.K.; Quah, C.K. J. Mol. Struct. 2015, 1092, 192-201.

24. Ramalingam,S.; Karabacak,M.; Periandy,S.; Puviarasan,N.; Tanuja,D. Spectrochim. Acta, Part A. 2012, 96, 207-220.

25. Shajikumar.; Ajay praveen kumar, A.; Raman, R.G. J. Chem. Pharm. Sci. 2017, 2063-2072.

26. Kleinman, D.A. Phys. Rev. 1962, 126(6) 1977-1979.

27. Ajaypraveenkumar, A.; Raman, R.G. J. Chem. Pharm. Sci. 2017, 1-9. 